\title{
O cirurgião de resgate
}

\author{
Walter J. GOMES ${ }^{1}$, Rui M. S. ALMEIDA², Domingo M. BRAILE ${ }^{3}$
}

O tratamento das doenças cardiovasculares vem recentemente experimentando grandes transformações, com a introdução de novas tecnologias intencionadas a trazer benefícios para os pacientes. Essas novas tecnologias incluem drogas, dispositivos, procedimentos e técnicas cirúrgicas, com a finalidade de reduzir invasividade e proporcionar qualidade de resultados comparável ou superior ao tratamento convencional [1].

Neste cenário de mudança, a cirurgia cardiovascular tem participado ativamente, consolidando a inserção e a atuação do cirurgião cardiovascular nos procedimentos endovasculares e minimamente invasivos nas áreas nas quais tradicionalmente já atua [2,3]. Entretanto, a introdução dessas novas tecnologias tem o potencial de substancialmente alterar a prática cirúrgica diária.

As intervenções em coração e grandes vasos para implante de dispositivos vêm gradualmente sendo realizadas por profissionais de outras especialidades médicas, com insuficiência ou mesmo ausência de formação e capacitação técnica para resolução de complicações que estão de modo inerente associadas a esses procedimento. Em conseqüência, dentre todas as atividades diárias do cirurgião cardiovascular, recentemente mais uma se somou, a intervenção para correção de complicações e insucessos de implante de dispositivos, configurando o cirurgião de resgate.

A introdução dessas novas técnicas e dispositivos, dezenas já em uso e centenas em desenvolvimento e teste, destinadas a abordar todos os tipos de defeitos cardíacos, vem acompanhada de marketing agressivo em mídia especializada e leiga, promovendo a disseminação rápida da informação na classe médica e público leigo, que demanda e pressiona o profissional médico.

Principalmente em construções de experiências iniciais e a chamada “curva de aprendizado”, as complicações são mais freqüentes e o cirurgião cardiovascular tem sido acionado cada vez mais para resoluções urgentes ou de emergência. Complicações como insuficiência valvar aguda por lesões de estruturas do aparelho valvar; dissecção de aorta; embolização ou mal-posicionamento de dispositivos que não podem ser recuperados; lacerações e roturas de câmaras cardíacas, grandes vasos e artérias coronárias; trombose e oclusão de vasos, aposições incompletas e vazamentos peri-próteses; estão entrando no rol das atividades do cirurgião, necessitando emprego de técnicas cirúrgicas novas e de recursos que nem sempre fazem parte da rotina cirúrgica.

Como grande número e modelos de dispositivos vêm chegando ao mercado, cada um com seu potencial de indução de complicações específico, isso obriga o cirurgião a se manter constantemente informado das características de cada dispositivo sendo lançado e em utilização, assim como as peculiaridades e potenciais de complicação.

Acrescente-se que a necessidade de intervenção da equipe cirúrgica ocorre geralmente em momentos inoportunos; períodos noturnos ou horários que interrompem cirurgias eletivas, colocando em risco os pacientes da programação eletiva diária; obrigando deslocamento rápido da equipe ou interferindo acentuadamente com a sua progração pré-estabelecida. Além disso, altera o horário de descanso e demandam maior sacrifício e empenho extraordinário dos cirurgiões cardiovasculares.

Comumente não há aviso prévio da equipe cirúrgica sobre o procedimento realizado e os pacientes não foram devidamente informados do procedimento, com os riscos, potenciais complicações e necessidade de cirurgia de urgência/emergência não satisfatoriamente explicados e detalhados.

Esses novos procedimentos, em muitas circunstâncias ainda com falta de evidência sobre os benefícios conferidos ao paciente, somente são oferecidos com a premissa de que em caso de insucesso, a cirurgia convencional pode ser realizada e restabelecer o prognóstico inicial.

Acrescente-se que em algumas situações o ônus do insucesso do procedimento pode recair sobre o cirurgião, principalmente em caso de desfecho fatal, já que são realizados em condição de urgência ou emergência e geralmente com o paciente em estado grave e de extremo risco. A partir do momento da cirurgia de resgate, o cirurgião cardiovascular passa a assumir todo o encargo pelos cuidados e as responsabilidades advindas da intervenção cirúrgica, inclusive com as seqüelas físicas e psíquicas que possam sobrevir em longo-prazo para o paciente, alem de lidar com as angústias e os aspectos emocionais da família.

Portanto, urge a necessidade de regulamentação desses procedimentos, nos quais cirurgiões e pacientes devem previamente ser amplamente informados. O termo de 
consentimento informado do paciente deve esclarecer todos os aspectos relacionados ao procedimento e possíveis complicações associadas, alem da eventual necessidade de uma cirurgia de resgate. Adicionalmente, a remuneração desses procedimentos especiais de resgate também necessita discussão suplementar, devendo ser contemplados com honorários especiais, já que não estão previstos nas tabelas em vigência e a própria Associação Médica Brasileira defende esta medida recomendando acréscimo para procedimentos realizados durante a noite ou nos finais de semana. Portanto, a remuneração de tais procedimentos que deve ser regulamentada de acordo com a gravidade que representem. A introdução da discussão multidisciplinar prévia do caso deve ser mandatória para permitir a organização da cirurgia de resgate em caso de insucesso e consequentemente evitar desfechos adversos ou mesmo fatal.

É imperioso que o assunto seja discutido amplamente no seio da SBCCV e com as autoridades competentes para que tais procedimentos sigam uma rotina em que haja participação de uma equipe completa capaz de oferecer ao paciente a máxima segurança.

\section{Agradecimento}

Os autores agradecem ao Dr. Fabrício Gaburro Teixeira, pela leitura do texto e recomendação no fundamento jurídico.

\section{REFERÊNCIAS}

1. Barbosa GV, Gomes WJ. A Sociedade Brasileira de Cirurgia Cardiovascular e a inserção dos cirurgiões cardiovasculares como especialistas endovasculares. Rev Bras Cir Cardiovasc 2009;24(2 Supp 1):3s.

2. Saadi EK. É possível formar um cirurgião endovascular? Rev Bras Cir Cardiovasc. 2007;22(1):III-IV.

3. Almeida RMS. O cirurgião cardiovascular como intervencionista. Rev Bras Cir Cardiovasc. 2009;24(2 Suppl 1):35-7s.

1. Diretor Científico da Sociedade Brasileira de Cirurgia Cardiovascular (SBCCV). Professor Associado Livre-Docente da Disciplina de Cirurgia Cardiovascular. Escola Paulista de Medicina - Universidade Federal de São Paulo. Editor Associado da Revista Brasileira de Cirurgia Cardiovascular / Brazilian Journal of Cardiovascular Surgery e São Paulo Medical Journal

2. Presidente do Departamento de Cirurgia Endovascular e Minimamente Invasiva da SBCCV. Professor Associado e Chefe da Disciplina de Cardiologia e Cirurgia Cardiovascular da Universidade Estadual do Oeste do Paraná (UNIOESTE).

3. Editor-Chefe da Revista Brasileira de Cirurgia Cardiovacular / Brazilian Journal of Cardiovascular Surgery. Professor Emérito e Pró-reitor de pós-graduação da Faculdade de Medicina de São José do Rio Preto (Famerp). Professor Livre-Docente da Unicamp. 